\title{
Prospective-controlled assessment of stress hormones and pain in patients undergoing myomectomy as performed by laparoscopy against laparotomy
}

George Pados ( $\nabla$ padosgyn@gmail.com )

Aristotle University of Thessaloniki School of Medicine https://orcid.org/0000-0002-3952-5483

Konstantinos Katrantsiotis

latriko Diavalkaniko Kentro

Dimitris Tsolakidis

1st Department of Obstetrics and Gynecology, "Papageorgiou" University Hospital, Aristotle University of

Thessaloniki, Thessaloniki, Greece

Kostantinos Almaloglou

"Diavalkaniko" Hospital, Centre for Gynecological Endoscopy, Thessaloniki, Greece

Spiros Gerou

"ANALYSIS" Diagnostic \& Research Centre, Thessaloniki, Greece

Research article

Keywords: laparoscopy, myomectomy, pain, surgical stress, laparotomy

Posted Date: May 11th, 2020

DOI: https://doi.org/10.21203/rs.3.rs-26683/v1

License: (c) (i) This work is licensed under a Creative Commons Attribution 4.0 International License.

Read Full License 


\section{Abstract}

\section{Purpose}

The objective of the study is to prospectively assess surgical stress and postoperative pain after myomectomy performed by laparoscopy versus laparotomy

\section{Methods}

This prospective, matched, multi-center observational study, took place in the Gynecological Department of the "Papageorgiou" University Hospital and the Centre for Gynecological Endoscopy, "Diavalkaniko" Hospital. Sixty women with symptomatic growth of known uterine leiomyomas or leiomyomas compromising the shape of the uterus participated in the study. Thirty women underwent laparoscopic myomectomy, and another thirty had removal of leiomyomas through laparotomy from November 2016 to February 2018. Three venous samples were obtained from each patient to determine stress hormones (one before surgery, the second at the end of the surgical procedure, and the third on the morning of the first postoperative day), and a questionnaire was administered on the first postoperative day, in which patients indicated the level of pain through a Visual Analog Scale for Pain (VASP).

\section{Results}

Adrenocorticotropic hormone (ACTH) and noradrenalin were significantly lower in the laparoscopic group on the first postoperative day $(12.68 \pm 9.97 \mathrm{pg} / \mathrm{ml}$ vs $15.90 \pm 9.02 \mathrm{pg} / \mathrm{ml}, \mathrm{p}<0.025)$ and $20.7 \pm 7.28 \mathrm{ng} / \mathrm{ml}$ vs $22.33 \pm 5.82 \mathrm{ng} / \mathrm{ml}, \mathrm{p}<0.027)$, respectively. There was no statistically significant difference in cortisol levels on the first postoperative day $(11.71 \pm 5.82 \mu \mathrm{g} / \mathrm{dl}$ vs $11.81 \pm 7.61 \mu \mathrm{g} / \mathrm{dl}, \mathrm{p}>0.94)$ and also for $\beta$ endorphin levels ( $4.88 \pm 1.57$ vs $4.91 \pm \mathrm{ng} / \mathrm{ml}, \mathrm{p}>0.61$ ). The postoperative pain was significantly lower in the laparoscopic group on the VASP scale ( $3.3 \pm 1.05$ vs $5.67 \pm 1.15, p<0.001$, respectively).

\section{Conclusion}

Laparoscopy is superior to laparotomy for the surgical removal of leiomyomas in terms of postoperative pain and surgical stress.

\section{Introduction}

The majority of open surgery methods today have corresponding laparoscopic methods. Laparoscopic surgery has undeniable advantages over laparotomy in terms of postoperative pain, recovery and patient's reintegration in their previous activities, lower incidence of de novo adhesion formation, and shorter hospitalization period [1-6]; therefore, the development of operative laparoscopy represents one of the most important milestones in the surgical field over the past 20 years. Regarding the stress of patients, although it has been reported to be less, the efficacy of the laparoscopic approach on the postoperative neuroendocrine and immune response, which largely determines the postoperative course of the patients, has not been adequately documented. Comparative studies of laparoscopy and 
laparotomy focus on pain monitoring for both methods rather than a prospective comparative assessment of stress hormones. There are quite a few studies that address the issue of surgical stress between these two methods $[7,8]$.

The aim of this prospective matched case-control trial is to assess surgical stress and postoperative pain by determining stress hormones and patient discomfort, as well as comparing the stress hormone response after myomectomy performed by laparoscopy versus laparotomy.

\section{Materials And Methods}

This prospective, matched, multi-center observational study was performed in the first Department of Obstetrics and Gynecology, "Papageorgiou” University Hospital in Thessaloniki, Greece, where all cases of laparotomic myomectomy were performed and at the Centre for Gynecological Endoscopy, "Diavalkaniko" private hospital, Thessaloniki, Greece, from November 2016 to February 2018. During the above period, all surgeries were performed by the same gynecologists, namely G.P for laparoscopic myomectomies and D.T for laparotomies and assisted by one of the other authors. Both the ethics committees of the two hospitals and the Aristotle University of Thessaloniki approved the study, and all patients signed an informed consent prior to surgery after a detailed explanation of the aim of the study.

Exclusion criteria involved allergies, endometriosis, endocrine disorders, previous surgical intervention in the lower abdomen, preoperative administration of gonadotrophin-releasing hormone analogues ( $\mathrm{GnRH}$ a), total number of fibroids greater than 3 , sum of the largest diameter of all 3 fibroids $\geq 15 \mathrm{~cm}$ and size of each one $>8 \mathrm{~cm}$. All surgical procedures were performed by the same two surgical teams as mentioned above, and the surgical technique in both open and laparoscopic surgery was identical.

Demographic data of each patient was recorded, as well as data regarding the history and indications of myomectomy. Three venous blood samples were received from each patient. The first was collected before surgery, the second was collected at the end of the surgical procedure after extubation while the patient was awake, and the third was collected on the morning of the first postoperative day. Blood samples were centrifuged, labeled and stored under deep-freezing conditions $\left(-90^{\circ} \mathrm{C}\right)$ until analysed simultaneously to avoid inter-assay and intra-assay variations. The study evaluated intraoperative and postoperative variations of the following stress-related markers: adrenocorticotropic hormone (ACTH), corticotropin-releasing factor (CRF), cortisol, noradrenalin and $\beta$-endorphin. Cortisol was measured by direct chemiluminescent technology (ADVIA Centaur Siemens), and ACTH was measured by a sequential chemiluminescent immunometric assay (Immulite 2001 - Siemens Healthcare Diagnostics Ltd). CRF and $\beta$-endorphin were measured by ELISA (Phoenix Pharmaceuticals Inc.), while noradrenaline was measured by the same method using the IBL International $\mathrm{GmbH}$ kit. Furthermore, a questionnaire was administered on the first postoperative day, in which patients were asked to indicate the level of pain they were experiencing through a Visual Analog Scale for Pain (VASP). Both surgical procedures were performed by experienced senior gynecologists under general endotracheal anesthesia, and the duration of each treatment was recorded. 
A total of 65 patients were included in the cohort, of which 30 were treated with laparoscopy, 30 with laparotomy and 5 were excluded due to exclusion criteria, such as different surgery outcomes, blood transfusion, major anaesthesia-related issues, etc. Indications for the interventions are: (i) symptomatic growth of uterine leiomyomas, leading to changes in menstrual profile (menometrorrhagia), (ii) Infertility if hysterosalpingography reveals a distortion of the uterine cavity, (iii) History of abortion or preterm delivery if the presence of the leiomyoma compromises the shape of the uterine cavity.

The Wilcoxon signed-rank and Mann-Whitney U-test were used for statistical analysis of correlated and independent paired variables, respectively, by means of SPSS v23 (SPSS, Inc. Chigago IL, USA), and the Kruskal-Wallis non-parametric statistical test and One-Way ANOVA parametric test where applicable for three or more independent variables, with a significance threshold of $p<0.05$. Where appropriate, the results were adjusted for multiple comparisons using Bonferonni and Tukey's post-hoc corrections. The reported data have \pm standard deviation and corresponding $95 \% \mathrm{Cl}$.

\section{Results}

The mean age of the patients was $37.9 \pm 5.66$ and $39.53 \pm 4.82$ for the laparoscopy and laparotomy groups, respectively $(p=N S)$.. and the BMI was $23.6 \pm 4.25$ and $26.20 \pm 5.88$, respectively $(p=N S)$. The operation time in the laparoscopic surgery group was $86.67 \pm 25.87 \mathrm{~min}$, while that in the laparotomy group was $70.67 \pm 23.81 \mathrm{~min}(\mathrm{p}=.028)$. According to the relevant treatment protocols, the hospitalization time presented a substantial difference for the surgical procedures, since it was one day for all laparoscopic procedures and 3 days for the laparotomy procedure $(p<0.01)$. The mean number of fibroids was $1.57 \pm 0.73$ and $1.63 \pm 0.89$ and the mean volume was $171.37 \pm 100.63 \mathrm{~cm}^{3}$ and $202.77 \pm 127.49$ $\mathrm{cm}^{3}(\mathrm{p}=\mathrm{NS})$ in the laparoscopy and laparotomy groups, respectively (Table 1$)$.With regard to cortisol expression for the laparotomy procedure, there is a significant difference between before $(13.7 \pm 7.54$ $\mu \mathrm{g} / \mathrm{ml}, 95 \% \mathrm{Cl}, 10.88$ to $16.51 ; \mathrm{p}<.05)$ and after $(19.85 \pm 10.31 \mu \mathrm{g} / \mathrm{ml}, 95 \% \mathrm{Cl}, 15.93$ to $23.77 ; \mathrm{p}=.05)$ the procedure. The cortisol expression on the first postoperative day was close to baseline levels $(11.89 \pm$ $7.61 \mu \mathrm{g} / \mathrm{ml}, 95 \% \mathrm{Cl}, 9.05$ to $14.73 ; \mathrm{p}<.05$; Figure 1$)$. .On the contrary, there is no statistically significant difference in cortisol expression before $(14.77 \pm 5.91 \mu \mathrm{g} / \mathrm{ml}, 95 \% \mathrm{Cl}, 12.57$ to 16.98$)$ and after (18.12 \pm $7.81 \mu \mathrm{g} / \mathrm{ml}, 95 \% \mathrm{Cl}, 15.20$ to $21.04 ; \mathrm{p}>.05)$ the laparoscopic procedure. Cortisol expression presented a difference only between the first postoperative day and exactly after the procedure $(11.70 \pm 5.82 \mu \mathrm{g} / \mathrm{ml}$, $95 \% \mathrm{Cl}, 9.53$ to 13.88; $\mathrm{p}$ <.05). The same expression pattern is evident for ACTH, with expression levels rising just after the laparotomy procedure (Before: $12.58 \pm 4.48 \mathrm{pg} / \mathrm{ml}, 95 \% \mathrm{Cl}, 10.90$ to 14.25; After: 20.72 $\pm 10.17 \mathrm{pg} / \mathrm{ml}, 95 \% \mathrm{Cl}, 16.32$ to $25.12, \mathrm{p}<.05)$ and falling on the first postoperative day $(11.17 \pm 5.63$ $\mathrm{pg} / \mathrm{ml}, 95 \% \mathrm{Cl}, 9.02$ to $13.31, \mathrm{p}<.05)$.

There is no difference in the laparoscopy procedure, with ACTH expression rising just after the procedure (Before: $14.12 \pm 5.72 \mathrm{pg} / \mathrm{ml}, 95 \% \mathrm{Cl}, 11.95$ to 16.30 ; After: $31.77 .72 \pm 16.58 \mathrm{pg} / \mathrm{ml}, 95 \% \mathrm{Cl}, 25.58$ to 37.96 , $\mathrm{p}<.001)$ and falling on the postoperative day $(15.90 \pm 9.027 \mathrm{pg} / \mathrm{ml}, 95 \% \mathrm{Cl}, 12.53$ to $19.27, \mathrm{p}<.001)$.It is worth noting that the CRF measurement of the laparotomy group on the first postoperative day was statistically significant compared to the pre-surgery measurement of the same group (Before: $.51 \pm .78$ 
$\mathrm{ng} / \mathrm{ml}, 95 \% \mathrm{Cl}, .22$ to $.81 ;$ After: $.63 .72 \pm .97 \mathrm{ng} / \mathrm{ml}, 95 \% \mathrm{Cl}, .27$ to $.99, \mathrm{p}<.05)$. No such difference was evident for the laparoscopic group. All other markers, namely noradrenalin and $\beta$-endorphin, showed no statistically significant expressive fluctuations between the groups.

Comparing the two procedures, there was no difference in either of the markers before the procedures. Postoperative laparoscopy ACTH levels were higher $(31.77 .72 \pm 16.58 \mathrm{pg} / \mathrm{ml}, 95 \% \mathrm{Cl}, 25.58$ to 37.96,) than their respective levels in the laparotomy procedure $(20.72 \pm 10.17 \mathrm{pg} / \mathrm{ml}, 95 \% \mathrm{Cl}, 16.32$ to 25.12 , $\mathrm{p}<.05)$. The same was evident for the first postoperative day, but with a marginally insignificant result (Laparoscopy: $15.90 \pm 9.027$ pg/ml, 95\% Cl, 12.53 to 19.27; Laparotomy: $11.17 \pm 5.63$ pg/ml, 95\% Cl, 9.02 to 13.31, $\mathrm{p}=.057)$.Noradrenalin showed differential expression levels on the postoperative day for the two procedures (Laparotomy: $22.33 \pm 5.82 \mathrm{ng} / \mathrm{ml}, 95 \% \mathrm{Cl}, 20.16$ to 24.50 ; Laparoscopy: $19.2 \pm 5.61 \mathrm{ng} / \mathrm{ml}$, $95 \% \mathrm{Cl}, 17.10$ to $21.29, \mathrm{p}<.05)$.

Postoperative pain was significantly lower in the laparoscopy group ( $3.3 \pm 1.05,95 \% \mathrm{Cl}, 2.90$ to 3.69$)$ compared to the laparotomy group $(5.67 \pm 1.15,95 \% \mathrm{Cl}, 5.23$ to $6.09 \mathrm{p}<.001)$ on the VASP scale on the first postoperative day (Figure 1).

\section{Discussion}

Most open surgeries now have a corresponding laparoscopic approach, which has undeniable advantages over laparotomy in terms of postoperative pain, recovery and patient's reintegration in their previous activities, lower incidence of de novo adhesion formation, shorter hospitalization period, and secondary financial benefits. [1-6]. With regard to the stress that patients are subjected to, although reported less frequently, the efficacy of the laparoscopic approach on postoperative neuroendocrine and immune responses, which largely determines postoperative pain, has not been sufficiently and scientifically proven. Comparative laparoscopy versus laparotomy studies focus on pain monitoring for both methods rather than a prospective comparative evaluation of stress hormones, and there are few studies on stress in these two methods $[7,8]$.

The purpose of this study is to objectively assess surgical stress by measuring the hormones released by patients during the surgical approach, document their choice for one or another method, and evaluate its impact on the patient's immediate postoperative course. To the best of our knowledge, this is the first study that evaluates the effect of an invasive method on body stress by monitoring the biochemical markers, such as ACTH, cortisol, $\beta$-endorphin, norepinephrine and CRF.

There was no difference in age and size of the excised fibroids between the two groups, but there was a noticeable difference in in surgical time, since the laparoscopic method consumed more time in most operations and this finding is in accordance with the literature [9]. The hospitalization time is a known advantage of the laparoscopic method compared to all types of open myomectomy and this was the case in our material [8]. 
Cortisol, a glucocorticoid hormone secreted by the $\mathrm{CRH}$ feedback and ACTH from the outer adrenal cortex [10], plays a key role in regulating the most basic physiological processes, as well as in stress responses [11-15]. In our findings, the hormone differs between the phases before and after surgery, and almost returns to preoperative levels and laparotomy, but not to laparoscopy, where cortisol expression differs only between the first postoperative day and exactly after the procedure. Our results are supported by a recent systematic review and meta-analysis of 71 studies on cortisol stress response in surgery [16]. The cortisol response varies between invasive and minimally invasive procedures, which lack a perioperative increase in cortisol, in contrast to the invasive ones that have more evident cortisol fluctuations in women and elderly patients under open surgery and general anesthesia.

ACTH, on the other hand, distinguishes between phases, before and after surgery, and almost returns to preoperative levels in both groups. There is a difference in expression levels right after surgery with a laparoscopy group having higher mean expression levels than the laparotomy group, which was previously reported [17].

On the contrary, the differential expression level of noradrenalin was found only on the post-operative day for the two procedures, with lower levels for the laparoscopy group. This finding requires further study.

$\beta$-endorphin is an endogenous opioid neuropeptide, but also a peptide hormone produced in the central nervous system (CNS) [18], which regulates the pain perception of human body mainly used to reduce stress, while maintaining homeostasis [19]. $\beta$-endorphin did not show a statistically significant difference between the two groups or during the procedure, which is consistent with the results of previous laparoscopic hysterectomy [20]. The effect of general anesthesia on $\beta$-endorphin levels can be considered here [21].

$\mathrm{CRF}$ is a peptide hormone that actively participates in stress responses [22-27]. CRF receptors and CRF itself have been identified in numerous extracellular brain sites [28]. CRF administration has also been shown to trigger activation of the pituitary-adrenal axis and the sympathetic nervous system, as well as stress-related behavioural characteristics [26]. Another difference between the two procedures was the measurement of CRF in the laparotomy group on the first postoperative day, since it was significantly different from the preoperative measurement. Of course, the laparoscopy group generally has a higher mean CRF, but does not change postoperatively which means patients no longer feel pain. This is a substantial difference between both methods in terms of pain and stress indicators. It is well known that CRF exerts analgesic effects in animals [22, 29] and humans [30, 31]. In addition, CRF and stress have been shown to induce the release of opioid peptides in inflammatory tissues [32,33]. Romero et al. (2017) [34] clearly demonstrated that deletion of the CRF1 receptor increases the inflammatory response after surgical excision, suggesting that the CRF/CRF1 receptor may be involved in the inflammatory response to tissue injury, which proves that our findings are correct.

A statistically significant difference between the scores on the visual analogue scale for pain (a onedimensional pain intensity measure) was also notable $[35,36]$ between the two groups, as the laparoscopic group had lower scores on the first postoperative day. These results are in line with the few 
studies to date that compare the two procedures with regard to stress $[7,17,37]$. In general, providing a $10 \mathrm{~mm}$ altered analgesic on a $100 \mathrm{~mm}$ metric VAS scale means a clinically significant improvement or reduction, while a VAS test below $33 \mathrm{~mm}$ means that there is an acceptable pain control (i.e., response) after surgery [38].

The main limitation of this study is the relatively small number of patients, although no related studies have been reported in the literature so far, and it would be interesting to compare other methods and perhaps more factors.

In conclusion, as in previous studies comparing the two methods, it is clear that laparoscopy offers a reduction in pain $[1-9,17,39-54]$, and stress level $[7,17,37]$. Our results are in agreement as well, providing a more detailed reference to the relationship between stress hormones and pain between the two surgical procedures. Laparoscopic surgery has been clearly shown to exert significant modifying effect on classical endocrine and metabolic responses, and while more data are needed, the clinical implication of these findings in relation to stress reduction, surgical outcome and active recovery enhances high position of laparoscopy in medical and surgical treatment options.

\section{Declarations}

\section{Ethics approval}

Both the ethics committees of the two hospitals and the Aristotle University of Thessaloniki approved the study

\section{Consent for publication}

Not applicable

Competing interest(s): The authors declare that they have no competing interests

\section{Funding}

There was no specific funding for this study

\section{Authors' contributions}

GP conceived the idea, performed all laparoscopic interventions and prepared the manuscript, DT performed the laparotomic myomectomies, KK and KA assisted in the laparoscopic myomectomies and assisted in the preparation of the manuscript and SG carried out the analyses. All authors listed approved the final version.

\section{Acknowledgements}

None 


\section{References}

1. Holzer A, Jirecek ST, Illievich UM, Huber J, Wenzl RJ (2006) Laparoscopic versus open myomectomy: a double-blind study to evaluate postoperative pain. Anesth Analg 102(5):1480-484.

2. Jin C, Hu Y, Chen X-c, et al (2009) Laparoscopic versus open myomectomy: a meta-analysis of randomized controlled trials. Eur J Obstet Gynecol Reprod Biol 145(1):14-21.

3. Mais V, Ajossa S, Guerriero S, et al (1996) Laparoscopic versus abdominal myomectomy: a prospective, randomized trial to evaluate benefits in early outcome Am J Obstet Gynecol 174(2):654658.

4. Miller CE (2000) Myomectomy: Comparison of open and laparoscopic techniques. Obstet Gynecol Clin North Am 27(2):407-420.

5. Stringer NH, Walker JC, Meyer PM (1997) Comparison of 49 laparoscopic myomectomies with 49 open myomectomies. J Am Assoc Gynecol Laparosc 4(4):457-464.

6. Moor D, Aggarwal G, Quiney N (2017) Systemic response to surgery. Surg Oxf Int Ed 35(4):220-223.

7. Muzii L, Marana R, Marana E, et al (1996) Evaluation of stress-related hormones after surgery by laparoscopy or laparotomy. J Am Assoc Gynecol Laparosc 3(2):229-234.

8. Bhave-Chittawar P, Franik S, Pouwer AW, Farquhar C (2014) Minimally invasive surgical techniques versus open myomectomy for uterine fibroids. Cochrane Database Syst Rev (10):CD004638.

9. Van der Kooij SM, Ankum WM, Hehenkamp WJ (2012) Review of nonsurgical/minimally invasive treatments for uterine fibroids. Curr Opin Gynecol Obstet 24(6):368-375.

10. Miller DB, O'Callaghan JP (2002) Neuroendocrine aspects of the response to stress. Metabolism: clinical and experimental 51(6 Suppl 1):5-10.

11. Saiah E (2008) The role of 11 beta-hydroxysteroid dehydrogenase in metabolic disease and therapeutic potential of 11 beta-hsd1 inhibitors. Curr Med Chem 15(7):642-649.

12. Frey FJ, Odermatt A, Frey BM (2004) Glucocorticoid-mediated mineralocorticoid receptor activation and hypertension. Curr Opin Nephrol Hypertens 3(4):451-458.

13. Bauer ME (2008) Chronic stress and immunosenescence: a review. Neuroimmunomodulation 15(46):241-250.

14. Atanasov AG, Odermatt A (2007) Readjusting the glucocorticoid balance: an opportunity for modulators of 11ß-hydroxysteroid dehydrogenase type 1 activity? Endocr Metab Immune Disord Drug Targets (Formerly Curr Drug Targets Immune Endocr Metabol Disord) 7(2):125-140.

15. Levine A, Zagoory-Sharon O, Feldman R, Lewis JG, Weller A (2007) Measuring cortisol in human psychobiological studies. Physiol Behav 90(1):43-53.

16. Prete A, Yan Q, Al-Tarrah K, et al (2018) The cortisol stress response induced by surgery: A systematic review and meta-analysis. Clin Endocrinol 89(5):554-567.

17. Marana E, Scambia G, Maussier ML, et al (2003) Neuroendocrine stress response in patients undergoing benign ovarian cyst surgery by laparoscopy, minilaparotomy, and laparotomy. J Am 
Assoc Gynecol Laparosc 10(2):159-165.

18. Malenka RC, Nestler E, Hyman S, Sydor A, Brown R (2009) Molecular neuropharmacology: a foundation for clinical neuroscience. NY: McGraw-Hill Medical.

19. Veening JG, Barendregt HP (2015) The effects of beta-endorphin: state change modification. Fluids Barriers CNS 12(1):3-11.

20. Rorarius MGF, Kujansuu E, Baer GA, et al (2006) Laparoscopically assisted vaginal and abdominal hysterectomy: comparison of postoperative pain, fatigue and systemic response. A case-control study. Eur J Anaesthesiol 18(8):530-539.

21. Villars PS, Kanusky RJT, Dougherty TB (2004) General anesthesia. AANA J 72(3):197-203..

22. Lariviere WR, Melzack R (2000) The role of corticotropin-releasing factor in pain and analgesia. Pain 84(1):1-12.

23. Rivier C, Brownstein M, Spiess J, Rivier J, Vale W (1982) In vivo corticotropin-releasing factor-induced secretion of adrenocorticotropin, beta-endorphin, and corticosterone. Endocrinology 110(1):272-278.

24. Rivier JE, Rivier CL (2014) Corticotropin-releasing factor peptide antagonists: design, characterization and potential clinical relevance. Front Neuroendocrinol 35(2):161-170.

25. Tan LA, Vaughan JM, Perrin MH, Rivier JE, Sawchenko PE (2017) Distribution of corticotropinreleasing factor (CRF) receptor binding in the mouse brain using a new, high-affinity radioligand. $J$ Comp Neurol 525(18):3840-3864.

26. Vale W, Rivier C, Brown MR, et al (2013) Chemical and biological characterization of corticotropinreleasing factor. Recent Prog Horm Res 39:245-270.

27. Vale W, Spiess J, Rivier C, Rivier J (1981) Characterization of a 41-residue ovine hypothalamic peptide that stimulates secretion of corticotropin and beta-endorphin. Science 213:1394-1397.

28. Aguilera G (2015) Stress adaptation and the hypothalamic-pituitary-adrenal axis. Mol Neuroendocrinol: From Genome to Physiology 375-403.

29. Vit JP, Clauw DJ, Moallem T, et al (2006) Analgesia and hyperalgesia from CRF receptor modulation in the central nervous system of Fischer and Lewis rats. Pain 121(3):241-260.

30. Likar R, Mousa SA, Steinkellner H, et al (2007) Involvement of intra-articular corticotropin-releasing hormone in postoperative pain modulation. Clin J Pain 23(2):136-142.

31. Matejec R, Uhlich H, Hotz C, et al (2005) Corticotropin-releasing hormone reduces pressure pain sensitivity in humans without involvement of $\beta$-endorphin $(1-31)$, but does not reduce heat pain sensitivity. Neuroendocrinology 82(3-4):185-197.

32. Labuz D, Schmidt Y, Schreiter A, et al (2009) Immune cell-derived opioids protect against neuropathic pain in mice. J Clin Invest 119(2):278-282.

33. Machelska H 2003) Functional evidence of pain control by the immune system. Adv Exp Med Biol 521:88-97.

34. Romero A, Garcia-Carmona JA, Laorden ML, Puig MM (2017) Role of CRF1 receptor in post-incisional plasma extravasation and nociceptive responses in mice. Toxicol Appl Pharmacol 332(Supplement 
C):121-128.

35. McCormack HM, Horne DJ, Sheather S (1988) Clinical applications of visual analogue scales: a critical review. Psychol Med 18(4):1007-1019.

36. Crichton N (2001) Visual analogue scale (VAS). J Clin Nurs 10(5):706-716.

37. Friedrich M, Rixecker D, Friedrich G (1998) Evaluation of stress-related hormones after surgery. Clin Exp Obstet Gynecol 26(2):71-75.

38. Myles P, Myles D, Galagher W, et al (2017) Measuring acute postoperative pain using the visual analog scale: the minimal clinically important difference and patient acceptable symptom state. BJA: Br J Anaesth 118(3):424-429.

39. Burton D, Nicholson G, Hall G (2004) Endocrine and metabolic response to surgery. Contin Educ Anaesth Crit Care Pain 4(5):144-147.

40. Cardozo ER, Clark AD, Banks NK, et al (2012) The estimated annual cost of uterine leiomyomata in the United States. Am J Obstet Gynecol 206(3):211 e1-9.

41. Cramer SF, Patel A (1990) The frequency of uterine leiomyomas. Am J Clin Pathol 94(4):435-438.

42. Desborough JP (2000) The stress response to trauma and surgery. Br J Anaesth 85(1):109-117.

43. Downes E, Sikirica V, Gilabert-Estelles J, et al (2010) The burden of uterine fibroids in five European countries. Eur J Obstet Gynecol Reprod Biol 152(1):96-102.

44. Ikhena DE, Bulun SE (2018) Literature review on the role of uterine fibroids in endometrial function. Reprod Sci 25(5):635-643.

45. LaMorte Al, Lalwani S, Diamond MP (1993) Morbidity associated with abdominal myomectomy. Obstet Gynecol 82(6):897-900.

46. Lethaby A, Vollenhoven B (2002) Fibroids (uterine myomatosis, leiomyomas) Clin Evid (7):16661678.

47. Levy BS (2008) Modern management of uterine fibroids. Acta Obstet Gynecol Scand 87(8):812-823.

48. Liu J, Cai L, Yang J, et al (2017) Optimized anesthesia to alleviate postoperative cognition decline in female middle-aged patients undergoing laparoscopic myomectomy: a pilot study. Neuropsychiatry (London). 7(5):675-683.

49. Sirkeci RF, Belli AM, Manyonda IT (2017) Treating symptomatic uterine fibroids with myomectomy: current practice and views of UK consultants. Gynecol Surg 14(1):11-16.

50. Stewart EA (2001) Uterine fibroids. Lancet 357(9252):293-298.

51. Tinelli A, Hurst BS, Hudelist G, et al (2012) Laparoscopic myomectomy focusing on the myoma pseudocapsule: technical and outcome reports. Hum Reprod 227(2):427-435.

52. Viswanathan M, Hartmann K, McKoy N, et al (2007) Management of uterine fibroids: an update of the evidence. Evid Rep Technol Assess (Full Rep) 154:1-12.

53. Wallach EE, Buttram VC, Reiter RC (1981) Uterine leiomyomata: etiology, symptomatology, and management. Fertil Steril 36(4):433-445. 
54. Wallach EE, Vlahos NF (2004) Uterine myomas: an overview of development, clinical features, and management. Obstet Gynecol 104(2):393-406.

\section{Table}

Table 1. Demographic and clinical characteristics of the study groups.

\begin{tabular}{llll} 
& Laparoscopy & Laparotomy & P value \\
\hline Age & $37.9 \pm 5.8$ & $39.5 \pm 4.8$ & NS \\
& & & \\
\hline BMI & $23.8 \pm 4.2$ & $26.2 \pm 5.8$ & NS \\
& & & \\
\hline $\begin{array}{l}\text { Myomas } \\
\text { (Mean } \pm \text { SD) }\end{array}$ & $1.5 \pm 0.7$ & $1.6 \pm 0.9$ & NS \\
\hline $\begin{array}{l}\text { Volume of myomas } \\
\text { (cm }{ }^{3} \text { ) }\end{array}$ & & & \\
& & & \\
\hline $\begin{array}{l}\text { Duration of surgery } \\
\text { (min) }\end{array}$ & $86.7 \pm 25.8$ & $70.7 \pm 23.8$ & 0.028 \\
\end{tabular}

\section{Figures}



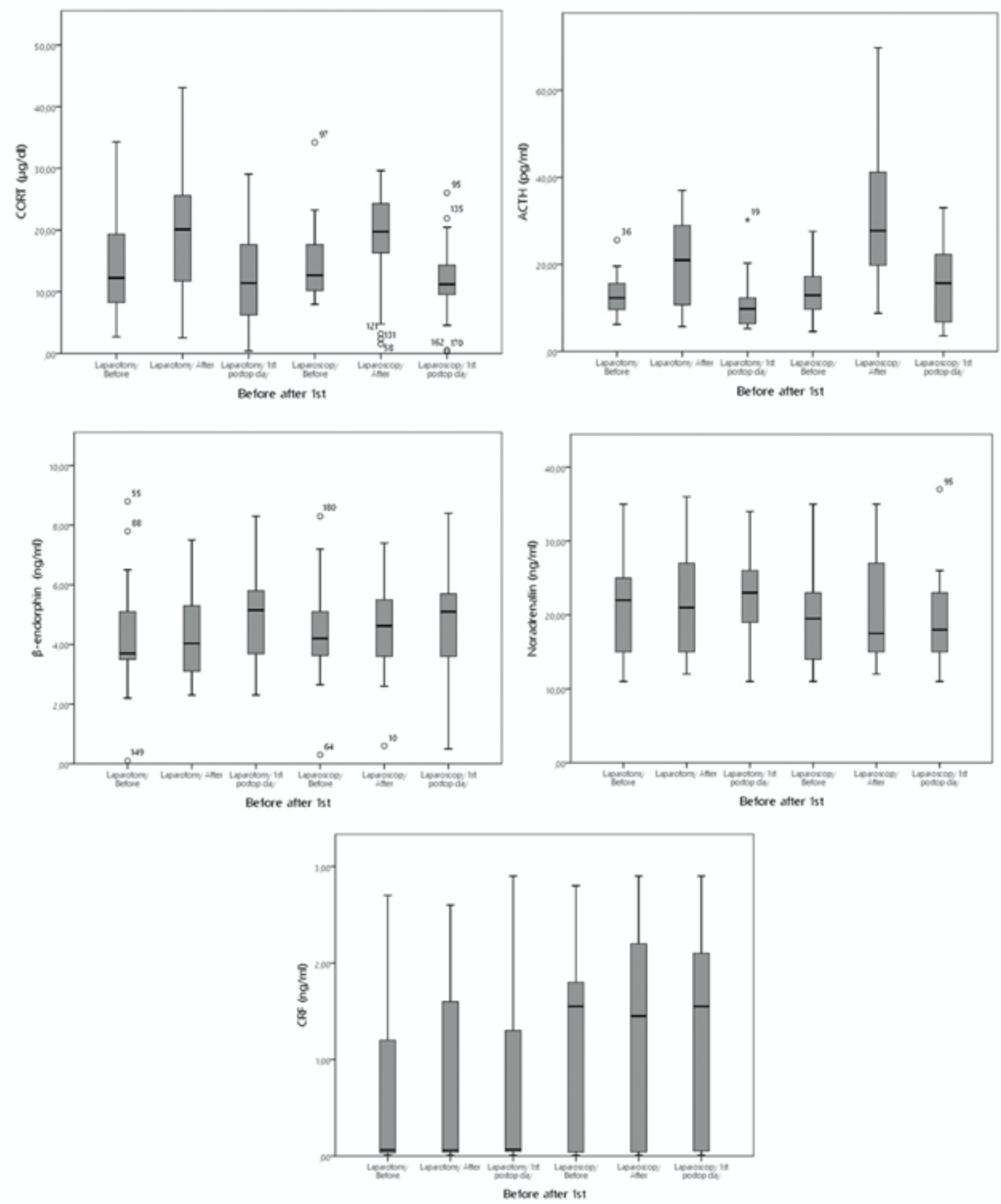

Figure 1

Stress related markers cortisol, ACTH, CRF, noradrenalin and b-endorphin in the two procedures for all days. 


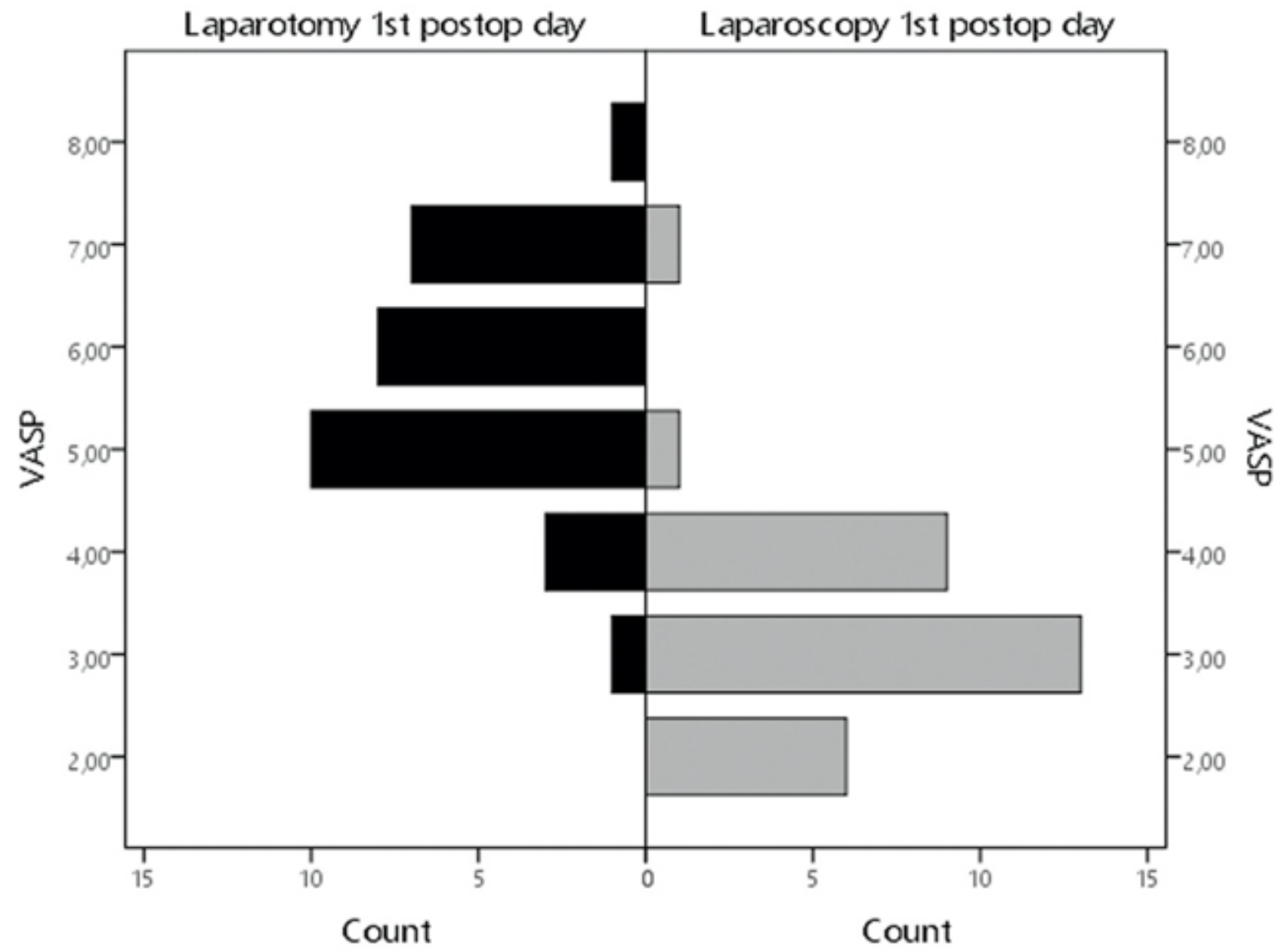

Figure 2

Visual Analog Scale of Pain between the two groups. Postoperative pain was significantly lower in the laparoscopy group $(3.3 \pm 1.05$ vs $5.67 \pm 1.15, p<0.001)$ on the VASP scale. 